\title{
Editor's notes: The interest group on qualitative data sums up and
}

continues

Welcome to the second issue of volume 43 of the IASSIST Quarterly (IQ 43:2, 2019).

With joy and pride the many people behind each issue of the IQ are here presenting a special issue. IASSIST has several interest groups of members committed to selected important areas under the umbrella of IASSIST. Be aware that you could become a member of an interest group (see: https://iassistdata.org/about/committees.html\#interest). If an interest area that you find important is not presently on this list, you are invited to start campaigning for the formation of a new interest group. The interest groups discuss and document their area and often arrange sessions at the IASSIST conferences. More formalization and continued documentation of the group's work are presented in conference papers and papers published here in the IQ.

This issue of the IQ is dedicated to papers on qualitative data presented by members of the group named 'Qualitative Social Science \& Humanities Data Interest Group' (QSSHDIG) and related practitioners. Lynda Kellam from the Cornell Institute for Social \& Economic Research and Mandy Swygart-Hobaugh of George State University end their leadership of the group with this special issue. Lynda Kellam and Celia Emmelhainz (qualitative research librarian at the University of California Berkeley) are guest editors of this issue and their introduction to the issue is following this page. I want to express my great thanks from the IQ to Lynda and Celia for taking the job of compiling a special issue. Support for qualitative data is important and a growing area. I trust you as readers will find valuable information and excellent advice in the papers of the many authors that are committed to improving the use and value of qualitative data.

Submissions of papers for the IASSIST Quarterly are always very welcome. We welcome input from IASSIST conferences or other conferences and workshops, from local presentations or papers especially written for the IQ. When you are preparing such a presentation, give a thought to turning your one-time presentation into a lasting contribution. Doing that after the event also gives you the opportunity of improving your work after feedback. We encourage you to login or create an author login to https://www.iassistquarterly.com (our Open Journal System application). We permit authors 'deep links' into the IQ as well as deposition of the paper in your local repository. Chairing a conference session with the purpose of aggregating and integrating papers for a special issue IQ is also much appreciated as the information reaches many more people than the limited number of session participants and will be readily available on the IASSIST Quarterly website at https://www.iassistquarterly.com. Authors are very welcome to take a look at the instructions and layout:

https://www.iassistquarterly.com/index.php/iassist/about/submissions

Authors can also contact me directly via e-mail: kbr@sam.sdu.dk. Should you be interested in compiling a special issue for the IQ as guest editor(s) I will also be delighted to hear from you.

Karsten Boye Rasmussen - June 2019

1/1 Rasmussen, Karsten Boye (2019) Editor's notes: The interest group on qualitative data sums up and continues, IASSIST Quarterly 43 (2), pp. 1-1. DOI https://doi.org/10.29173/iq961 